\title{
ARE CONDITIONAL AND DISJUNCTION REALLY COMPARABLE? ${ }^{1}$
}

\author{
¿Son el condicional y la disyunción realmente comparables? \\ Miguel López Astorga *
}

\begin{abstract}
Liu and Chou theorize that the rules of Modus Ponens and Modus Tollens have equivalent disjunctive forms. They present an experiment using these forms and conclude that, if applied to disjunctive inferences, the rule of Modus Tollens is not more difficult than the rule of Modus Ponens. Their explanation is based on a successive-conditionalization framework, but, in this paper, it is argued that their results can be interpreted according to, at least, another two theories, the mental models theory and the formal rules theory, and that, therefore, their experiment does not necessarily prove their theses.
\end{abstract}

Keywords: Conditional, disjunction, inference, Modus Ponens, Modus Tollens.

\footnotetext{
${ }^{1}$ This paper is a result of Project $\mathrm{N}^{\circ} 1120007$, "El procesamiento de enunciados condicionales en los estudiantes de Educación Media: Un estudio a partir de la tarea de selección de Peter Wason”, supported by FONDECYT (National Fund for Scientific and Technological Development), Government of Chile. The autor and lead researcher of this Project would like to thank FONDECYT and the Government of Chile for their help in funding this paper.

* Instituto de Estudios Humanísticos "Juan Ignacio Molina”, Universidad de Talca. Talca, Chile. Correo electrónico: milopez@utalca.cl

Recibido el 12 de mayo de 2013. Aceptado el 3 de junio de 2013.
} 


\section{RESUMEN}

Liu y Chou plantean que las reglas del Modus Ponens y el Modus Tollens poseen formas disyuntivas equivalentes, proponen un experimento utilizando tales formas y concluyen que, si se aplica a inferencias disyuntivas, la regla del Modus Tollens no es más difícil que la del Modus Ponens. Su explicación se basa en un marco de condicionalizacion sucesiva, pero, en este trabajo, se argumenta que sus resultados se pueden interpretar de acuerdo con, al menos, otras dos teorías, la teoría de los modelos mentales y la teoría de las reglas formales, y que, por tanto, su experimento no prueba necesariamente sus tesis.

Palabras clave: Condicional, disyunción, inferencia, Modus Ponens, Modus Tollens.

\section{INTRODUCTION}

Liu and Chou present a surprising finding. According to them, using the rule of Modus Tollens (from now on, MT) is not more difficult than using the rule of Modus Ponens (from now on, MP) if these rules are applied to disjunctive sentences that can be considered to be logically equivalent to conditional sentences.

As it is well-known, MP has this structure:

If $\mathrm{p}$, then $\mathrm{q}$

$\mathrm{p}$

Therefore, $\mathrm{q}$

On the other hand, the structure of MT is the following:

If $\mathrm{p}$, then $\mathrm{q}$

not $\mathrm{q}$

Therefore, not $\mathrm{p}$ 
It is also well-known that, usually, MT is considered to be a more difficult rule than MP (for example, Johnson-Laird, 2006; Byrne \& Johnson-Laird, 2009). For this reason, it can be thought that, in principle, the forms of these rules created by Liu and Chou should be similarly different with regards to their degrees of difficulty.

Liu and Chou, as said, argue the opposite. Nevertheless, their approach can be questioned. They present an experiment and use its results to support their thesis, but these results can be interpreted according to, at least, two different alternative approaches. The first one of these is the approach established by the mental models theory (Byrne \& Johnson-Laird, 2009; Johnson-Laird, 1993, 2001, 2006, 2012; Johnson-Laird \& Byrne, 1995, 2002; Johnson-Laird, Byrne \& Girotto, 2009; Johnson-Laird, Byrne \& Schaeken, 1992; Johnson-Laird \& Hasson, 2003; Orenes \& Johnson-Laird, 2012). The mental models theory states that individuals reason by means of models and that these models represent the different possibilities consistent with both the premises and the conclusions of the inferences faced by them. The second approach, which seems to hold that the human mind follows formal logical rules and to raise a material interpretation of conditionals, is related to the assumptions assumed by several authors that do not necessarily offer the same arguments. Some of those authors are Henlé (1962), O'Brien (2009), or Rips (1994), and, maybe, frameworks such as the one offered by Beth and Piaget (1966) can also be linked to this approach.

How these two theories can also explain the results of Liu and Chou's experiment is going to be shown later. Nonetheless, prior to this, it seems appropriate, firstly, to present the theses made by Liu and Chou (2012), to describe their experiment and to comment how they interpreted their results.

\section{TWO CONDITIONALIZATION PROCESSES FOR INFERENCES}

Liu and Chou think that, when individuals face inferences, two conditionalization processes happen. According to their view, in the case of MP, the first conditionalization leads individuals to consider the probability of $\mathrm{q}$, that is, the conclusion, if $\mathrm{p}$, that is, the second premise, is true. In this way, the first conditionalization leads to consider $\mathrm{P}(\mathrm{q} \mid \mathrm{p})$. In this first process, as it can be 
noted, individuals' general knowledge has a clear influence. On the other hand, the second conditionalization is the process that leads individuals to accept the first premise as a true premise. "Thus, the second conditionalization for MP is represented by $\mathrm{P}(p$ therefore $q \mid$ if $p$ then $q)$ )" (Liu \& Chou, 2012: 692, italics in text).

Based on these theses, it is not difficult to deduce that they think, equally, that, in the case of MT, the first conditionalization leads to consider P(not $\mathrm{p} \mid$ not $\mathrm{q}$ ), and the second conditionalization can be represented by $\mathrm{P}$ (not q therefore not $\mathrm{p} \mid$ if $\mathrm{p}$ then $\mathrm{q})$.

The fact that general knowledge has an important influence on the first conditionalization can be obvious if an example is thought. In the case of MP, if the first premise is If the apple is ripe then it will fall from the tree, the second premise is The apple is ripe, and the conclusion is The apple will fall from the tree, in the first conditionalization, in which the first premise is not considered, individuals can only use their general knowledge about apples, ripening processes and trees in order to determine $\mathrm{P}$ (the apple will fall from the tree $\mid$ the apple is ripe). And something similar can be said in the case of MT if the second premise is the apple will not fall from the tree, the conclusion is The apple is not ripe, and what must be determined is $\mathrm{P}$ (the apple is not ripe | the apple will not fall from the tree).

If Liu and Chou (2012) are right, by transforming a conditional into an equivalent expression, for example, into a disjunction in which its first term is denied, it is possible to check whether or not logical forms have an influence on the second conditionalization. Liu and Chou (2012) present two experiments related to this issue, but, for this paper, their first experiment is the most interesting one because an experiment like this is the experiment that leads to conclude that, if MP and MT are applied to disjunctive sentences (of course, equivalent to conditional sentences), it can be noted that MT is not more difficult to apply than MP. The next part presents the general characteristics of that experiment and its results. 


\section{CONDITIONAL SENTENCES AND EQUIVALENT DISJUNCTIVE SENTENCES}

Two kinds of problems are used by Liu and Chou (2012). The first kind (reduced problems) only shows the participants the second premise of an inference and the conclusion of such an inference. Thus, this kind of problem is related to the first conditionalization because, in the absence of further information (the second premise), the second conditionalization is not possible. Based on one of the examples indicated by Liu and Chou (2012), it can be said that problems similar to the following were used:

For MP: Given that it is not daytime now, how probable is it that it is night time?

For MT: Given that it is not night time, how probable is it that it is daytime now?

The second kind of problem (complete problems) is different. These problems include, moreover, the first premise, which, in some cases, is a conditional and, in other cases, a disjunction. In this way, based on the same previous example, it can be said that some of these problems with conditionals were as follows:

For MP: "If it is not daytime now, it is night time" (Liu \& Chou, 2012: 690, italics added).

Given that it is not daytime now, how probable is it that it is night time?

For MT: "If it is not daytime now, it is night time" (Liu \& Chou, 2012: 690, italics added).

Given that it is not night time now, how probable is it that it is day time?

Taking into account that a sentence such as If $p$ then $q$ is equivalent to a sentence such as Either not p or q, according to Liu and Chou (2012), an example of inference with disjunctive sentence corresponding to MP (from now on, $\mathrm{MP}^{\prime}$ ), raised from the sentence If it is not daytime now, it is night time, could be this one:

"It is now daytime or night time" (Liu \& Chou, 2012: 690, italics added). Given that it is not daytime now, how probable is it that it is night time? 
On the other hand, based on the same sentence and, in the same way, following Liu and Chou (2012)'s assumptions, an example of inference with disjunctive sentence corresponding to MT (from now on, MT'), could be as follows:

"It is now daytime or night time" (Liu \& Chou, 2012: 690, italics added). Given that it is not night time now, how probable is it that it is daytime?

Thus, Liu and Chou (2012) ask their participants to solve problems (both reduced and complete) related to MP, MT, MP', and $\mathrm{MT}^{\prime}$. Actually, this experiment has a much broader scope because it also includes exercises linked to conditional fallacies such as affirming the consequent fallacy and denying the antecedent fallacy, and, equally, variables such as the sufficiency and the necessity of the conditional sentences (and, in the same way, the sufficiency and the necessity of the equivalent disjunctive sentences) are controlled. Nevertheless, for this paper, the most relevant results are the results directly related to MP, MT, $\mathrm{MP}^{\prime}$, and $\mathrm{MT}^{\prime}$, and the difference between them.

Interesting results in that regard can be, for example, that MP shows a better execution than MT, and that MP also shows a better execution than MP', and also that the execution of $\mathrm{MP}^{\prime}$ is not significantly different to the execution of $\mathrm{MT}^{\prime}$. Liu and Chow think that, according to the material interpretation of conditionals, the execution of MP should be similar to the execution of MP', because, as indicated, a sentence such as If it is not daytime now, it is night time is equivalent to a sentence such as It is now daytime or night time. In their view, this fact and the fact that the executions of $\mathrm{MP}^{\prime}$ and $\mathrm{MT}^{\prime}$ are similar (remember that the first premise included in $\mathrm{MP}^{\prime}$ and $\mathrm{MT}^{\prime}$ is the same premise) can lead to accepting that the second conditionalization is an important process that happens when individuals think about inferences. In this way, it seems that, according to Liu and Chou (2012), if the executions of MP and MP' are different, this can only be explained by means of the second conditionalization, because the only difference between MP and MP' is their first premise, that is, the premise that is considered in the second conditionalization. Equally, it seems that, in their opinion, if the execution of $\mathrm{MP}^{\prime}$ and $\mathrm{MT}^{\prime}$ is similar, this can only be explained by means of the second conditionalization, because these are exercises in which 
the first premise, that is, the premise considered in the second conditionalization, is the same premise.

Nonetheless, those results can also be explained from other frameworks or approaches. As mentioned above, the fact that the execution of MP is better than the execution of MT is a fact which the literature explains. On the other hand, the better execution of MP with regards to $\mathrm{MP}^{\prime}$ and the similar execution of $\mathrm{MP}^{\prime}$ and $\mathrm{MT}^{\prime}$ can be explained from, at least, two different theories, the mental models theory and the formal rules theory. The next part presents a possible explanation of these results following the mental models theory.

\section{CONDITIONALS, DISJUNCTIONS, AND THE MENTAL MODELS THEORY}

Byrne and Johnson-Laird (2009), for example, explain, from the mental models theory, why MT is more difficult than MP. They state that, when an individual faces a conditional sentence, swiftly and immediately, he imagines a first model consistent with such a sentence in which its two terms, that is, the antecedent and the consequent, are true. This means that, in the previous example (If it is not daytime now, it is night time), the first immediate and intuitive model is the appropriate model for MP, that is, this one:

not daytime night time

Based on the mental models theory, another possible model consistent with the sentence If it is not daytime now, it is night time can only be thought after a more complex process of analysis and reflection. This second model could be as follows:

daytime not night time

Note that MT needs this second model and that MT cannot be applied without it. That circumstance alone explains why, from the mental models theory, MP is easier than MT, because that theory states that the model corresponding to MT needs a more complex thought process. 
According to this theory, it is also obvious why MP is equally easier than $\mathrm{MP}^{\prime} . \mathrm{MP}^{\prime}$ refers to a disjunction (its first premise is a disjunctive sentence) and disjunctions, if they are exclusive, need two models, as indicated, for example, by Johnson-Laird (2012). Of course, a sentence such as It is now daytime or night time is an exclusive disjunction, because it is not possible that, at the same time, it is daytime and it is night time, and its two models are these:

$$
\begin{array}{ll}
\text { not daytime } & \text { night time } \\
\text { daytime } & \text { not night time }
\end{array}
$$

The second premise of $\mathrm{MP}^{\prime}$ (It is not daytime) eliminates the second model, but it is important to note that this process is more difficult than the process corresponding to MP, since MP needs one model and MP' needs two models, and this fact can be accepted as an explanation of why MP is easier than MP'.

Finally, it is not difficult to understand that, according to the mental models theory, $\mathrm{MP}^{\prime}$ and $\mathrm{MT}^{\prime}$ offer a similar execution. Both $\mathrm{MP}^{\prime}$ and $\mathrm{MT}^{\prime}$ include, as a first premise, a disjunctive sentence that leads to two models, which are the same previous models, that is, which are:

$$
\begin{array}{ll}
\text { not daytime } & \text { night time } \\
\text { daytime } & \text { not night time }
\end{array}
$$

In $\mathrm{MP}^{\prime}$, the second premise, as mentioned, eliminates the second model and, in $\mathrm{MT}^{\prime}$, the second premise (It is not night time) eliminates the first model in the same way. The only difference between $\mathrm{MP}^{\prime}$ and $\mathrm{MT}^{\prime}$ is, therefore, the eliminated model, but, essentially, both $\mathrm{MP}^{\prime}$ and $\mathrm{MT}^{\prime}$ are equally complex, and both $\mathrm{MP}^{\prime}$ and $\mathrm{MT}^{\prime}$ need, substantially, the same mental process. In the two cases, two models are needed and one of them is eliminated by the second premise.

Thus, it is clear that the mental models theory can explain the results offered by Liu and Chow (2012) and that it is not necessary to accept their assumptions or their idea related to a second conditionalization to explain their results. But, as indicated above, the mental models theory is not the only theory that can explain these results. The formal rules theory can also explain this. This is shown in the next section. 


\section{CONDITIONALS, DISJUNCTIONS, AND THE FORMAL RULES THEORY}

Although it is important to pay attention to the fact that, at present, the formal rules theory (which is, as mentioned, a theory based on formal logic rules) is not accepted as much as the mental models theory, it can be interesting to show that the formal rules theory can also offer an alternative explanation of the results presented by Liu and Chou (2012). As Byrne and Johnson-Laird (2009) recall, the formal rules theory can explain why MT is more difficult than MP. According to the formal rules theory, if MT is applied, an additional rule, the rule of Reductio ab absurdum (from now on, RA), is needed, and, based on the explanation provided by Byrne and Johnson-Laird (2009), it can be stated that the structure corresponding to MT which has been indicated above (premises: If $p$ then $q$ and not $q$; conclusion: not $p$ ) is, following the formal rules theory, an abbreviated structure. MP is easy because its structure is really simple (premises: If $p$ then $q$ and $p$; conclusion: $q$ ), but MT needs additional steps related to the application of RA (steps 3, 45, and 6 of the deduction presented in appendix 1), which consists of, after a supposition has been accepted ( $p$, step 3 of the deduction presented in appendix 1), concluding its denial (not p, step 6 of the deduction presented in appendix 1) provided that a contradiction is found ( $q$ and not $q$, step 5 of the deduction presented in appendix 1). Therefore, it is obvious that the formal rules theory can offer an explanation of why MP is easier than MT.

But the formal rules theory can also explain why $\mathrm{MP}^{\prime}$ is more difficult than MP. According to material interpretation, accepted by the formal rules theory, a sentence such as If not $p$ then $q$ is equivalent to a sentence such as $p$ or $q$ (a disjunction in which the antecedent is denied in the first term and the second term is the consequent). Nonetheless, in formal logic, it is difficult to draw a conclusion from a disjunction because the rule which allows eliminating a disjunction is very complex, even more so than for MT. The use of such a rule requires that the two terms of the disjunction are taken as suppositions, and that the conclusion is inferred, separately, from each of them. Thus, the structure of the rule that allows concluding $q$ from premises such as $p$ or $q$ and not $p$ needs many steps (including, as it can be seen in appendix 2, two applications of RA), and, in this way, it is clear why, in the view corresponding to the formal rules theory, MP, 
which is a simple rule, is easier than MP'.

Moreover, it is not difficult to check that $\mathrm{MT}^{\prime}$ needs the use of that same rule of elimination required for $\mathrm{MP}^{\prime}$, and as steps as $\mathrm{MP}^{\prime}$ (including, as it can be seen in appendix 3, two applications of RA), in order to conclude $p$ from $p$ or $q$ and not $q$. Therefore, the similarity between the deduction related to $\mathrm{MP}^{\prime}$ and the deduction linked to $\mathrm{MT}^{\prime}$ is obvious, and, based on the formal rules theory, this fact, by itself, can explain why $\mathrm{MP}^{\prime}$ is as difficult as $\mathrm{MT}^{\prime}$.

\section{CONCLUSIONS}

Undoubtedly, Liu and Chow (2012) offer an interesting interpretation of their results. However, such results can be interpreted following other approaches, and, due to this, it is not clear that the two conditionalization processes raised by them can explain conditional reasoning.

The framework suggested by Liu and Chou (2012), the mental models theory and the formal rules theory are opposed theories that can explain the same results. This fact leads to thinking that there are problems about reasoning that have not been solved. One of these unsolved problems is the conditional reasoning problem. But, if such a particular problem is not solved, it can be said that the logical reasoning problem, which is a more general problem, also needs to be solved. Therefore, more research in this regard is needed.

Of course, despite the fact that both the mental models theory and the formal rules theory can offer an explanation of the results presented by Liu and Chou (2012), it is possible to continue thinking, as a possibility, that the approach referring to inferential processes held by Liu and Chou is a valid and correct approach. Nonetheless, if this is so, it needs to be demonstrated by means of more conclusive proof and evidence, because the disjunctive structures that they allocate to their $\mathrm{MP}^{\prime}$ and their $\mathrm{MT}^{\prime}$ are extremely similar and, thus, these structures do not clearly prove their theses.

For the time being, it must be accepted that three different frameworks (the two conditionalizations approach, the mental models theory, and the formal 
rules theory) are consistent with the results found by Liu and Chou (2012), and that, at present, there are no clear indications that can help decide which framework must be supported. Nevertheless, it is important to remember that the mental models theory is much more widely accepted than the formal rules theory. In fact, the mental models theory is proving to be very successful and, by means of such a theory, many cognitive phenomena are being explained.

\section{REFERENCES}

Beth, Evert Willem \& Piaget, Jean. Mathematical Epistemology and Psychology. Dordrecht: Reidel, 1966.

Byrne, Ruth M. J. \& Johnson-Laird, Philip N. “'If' and the problems of conditional reasoning", Trends in Cognitive Science 13/7 (2009): 282-287.

Henlé, Mary. "On the relation between logic and thinking", Psychological Review 69 (1962): 366-378.

Johnson-Laird, Philip N. Mental Models. Towards a Cognitive Science on Language, Inference and Consciousness. Cambridge: Cambridge University Press, 1983.

Johnson-Laird, Philip N. "Mental models and deduction", Trends in Cognitive Science 5 (2001): 434-442.

Johnson-Laird, Philip N. How We Reason. Oxford: Oxford University Press, 2006.

Johnson-Laird, Philip N. "Inference with mental models". In Keith James Holyoak and Robert G. Morrison (eds.). The Oxford Handbook of Thinking and Reasoning. New York: Oxford University Press, (2012): 134-145.

Johnson-Laird, Philip N. \& Byrne, Ruth M. J. “A model point of view”, Thinking and Reasoning 1 (1995): 339-350.

Johnson-Laird, Philip N. \& Byrne, Ruth M. J. "Conditionals: a theory of meaning, inference, and pragmatics", Psychological Review 109 (2002): 646-678. 
Johnson-Laird, Philip N.; Byrne, Ruth M. J. \& Girotto, Vittorio. "The mental model theory of conditionals: a reply to Guy Politzer", Topoi 28 (2009): 75-80.

Johnson-Laird, Philip N.; Byrne, Ruth M. J. \& Schaeken, Walter S. "Propositional reasoning by model”, Psychological Review 99 (1992): 418-439.

Johnson-Laird, Philip N. \& Hasson, Uri. "Counterexamples in sentential reasoning", Memory and Cognition 31 (2003): 1105-1113.

Liu, In-mao \& Chou, Ting-hsi. "A successive-conditionalization approach to disjunctive and syllogistic reasoning", Psychological Research 76 (2012): 676-692.

O'Brien, David. "Human reasoning requires a mental logic", Behavioral and Brain Sciences 32 (2009): 96-97.

Orenes, Isabel \& Johnson-Laird, Philip N. "Logic, models and paradoxical inferences", Mind and Language 27/4 (2012): 357-377.

Rips, Lance J. The Psychology of Proof. Cambridge: Cambridge University Press, 1994. 


\section{APPENDIX 1}

Deduction corresponding to MT

1.- If $\mathrm{p}$ then $\mathrm{q}$ (premise)

2.- not $\mathrm{q}$ (premise)

3.- $\mathrm{p}$ (supposition)

4.- $\mathrm{q}$ (MP, steps 1 and 3)

5.- $\mathrm{q}$ and not $\mathrm{q}$ (introduction of a conjunction, steps 2 and 4 )

6.- not p (RA, steps 3-5)

\section{APPENDIX 2}

Deduction corresponding to $\mathrm{MP}^{\prime}$

1.- $\mathrm{p}$ or $\mathrm{q}$ (premise)

2.- not $\mathrm{p}$ (premise)

3.- $\mathrm{p}$ (supposition)

4.- not $\mathrm{q}$ (supposition)

5.- $\mathrm{p}$ and not $\mathrm{p}$ (introduction of a conjunction, steps 2 and 3 )

6.- q (RA, steps 4-5)

7.- q (supposition)

8.- not q (supposition)

9.- $\mathrm{q}$ and not $\mathrm{q}$ (introduction of a conjunction, steps 7 and 8)

10.- q (RA, steps 8-9)

11.- q (elimination of a disjunction, steps 1, 3-6, 7-10) 


\section{APPENDIX 3}

Deduction corresponding to $\mathrm{MT}^{\prime}$

1.- $\mathrm{p}$ or $\mathrm{q}$ (premise)

2.- not $\mathrm{q}($ premise $)$

3.- $\mathrm{p}$ (supposition)

4.- not $\mathrm{p}$ (supposition)

5.- $\mathrm{p}$ and not $\mathrm{p}$ (introduction of a conjunction, steps 3 and 4)

6.- p (RA, steps 4-5)

7.- q (supposition)

8.- not $\mathrm{p}$ (supposition)

9.- $\mathrm{q}$ and not $\mathrm{q}$ (introduction of a conjunction, steps 2 and 7)

10.- p (RA, steps 8-9)

11.- $\mathrm{p}$ (elimination of a disjunction, steps, 1, 3-6, 7-10) 